\title{
A polymerase tautomeric model for radiation induced bystander effects: a model for untargeted base substitution mutagenesis during error prone and SOS replication of double stranded DNA containing thymine and adenine in rare tautomeric forms
}

\begin{abstract}
Currently, untargeted mutations are studied in the context of bystander effects. Up to now the nature and mechanisms of formation of untargeted mutations is poorly understood. Untargeted base substitution mutations are base substitution mutations then one or some nucleotides are inserted in DNA molecule on, so called, undamaged sites of DNA. Here the polymerase-tautomeric models of ultraviolet mutagenesis and bystander effects are developed. The mechanisms of untargeted base substitution mutations formation caused by cis-syn cyclobutane thymine dimers and bases pairs of adenine-thymine or thymine-adenine in rare tautomeric forms that are in small neighbor from any cyclobutane dimers are proposed. Five rare tautomeric forms may form for thymine and adenine. These rare tautomeric forms will be stable if corresponding nucleotides are part of cyclobutane pyrimidine dimers or are in small neighbor of the cyclobutane dimers and during DNA synthesis. Structural analysis of bases incorporation shown that adenine in rare tautomeric form $\mathrm{A} 1 *$ may result in untargeted homologous transversion $\mathrm{T}-\mathrm{A} \rightarrow \mathrm{A}-\mathrm{T}$. Thymine in rare tautomeric form $\mathrm{T} 1 *$ may result in untargeted transition $\mathrm{A}-\mathrm{T} \rightarrow \mathrm{G}-\mathrm{C}$ or untargeted homologous transversion $\mathrm{A}-\mathrm{T} \rightarrow \mathrm{T}-\mathrm{A}$. Molecules of the thymine in rare tautomeric form $\mathrm{T} 4 *$ may result in transversion $\mathrm{A}-\mathrm{T} \rightarrow \mathrm{C}-\mathrm{G}$ only. Thymine in rare tautomeric form $\mathrm{T} 5 *$ may result in untargeted transversion $\mathrm{A}-\mathrm{T} \rightarrow \mathrm{C}-\mathrm{G}$ or untargeted homologous transversion $\mathrm{A}-\mathrm{T} \rightarrow \mathrm{T}-\mathrm{A}$. Thus, molecules of adenine and thymine in definite tautomeric forms are in small neighbor from any cyclobutane pyrimidine dimers may result in untargeted base substitution mutations.
\end{abstract}

Volume 2 Issue 2 - 2017

\section{HA Grebneva}

Donetsk Physical and Technical Institute National Academy of Science of Ukraine, Ukraine

Correspondence: Donetsk Physical and Technical Institute National Academy of Science of Ukraine, 03680 Kiev, Nauky av. 46,Ukraine,Email grebneva@gmail.com

Received: February 19, 2017 | Published: April 12, 2017

\section{Introduction}

The major underlying cause of mutations in cancer is DNA damage. The formation of mutations is the main cause of genetic diseases and cancer, as well as the major cause of aging. ${ }^{2}$ Understanding of processes that occur during the formation of mutations, it is necessary for the developing of strategies and methods to combat cancer, as well as for the development of prevention methods that would contribute to a decrease in the probability of occurrence of cancer and hereditary diseases.

Radiation-induced genomic instability is a modification of the cell genome found in the progeny of irradiated somatic and germ cells but that is not confined on the initial radiation-induced damage and may occur de novo many generations after irradiation. ${ }^{3-5}$ It has been shown that radiation can, by itself, induce a type of genomic instability in cells, which enhances the rate at which mutations and other genetic changes arise in the descendants of the irradiated cell after many generations of replication. ${ }^{4}$ Genomic instability leads to the formation of malignant tumors. Genomic instability is the process whereby gene mutations increase. Although radiation-induced genomic instability has been studied for years, many questions remain to be answered.
Delayed mutations and untargeted mutations are two features of genomic instability. ${ }^{7}$ In recent decades untargeted and delays mutations are combined in bystander effects. ${ }^{8-10}$ Genomic instability and the bystander effect have been linked experimentally. ${ }^{11}$ It is believed now that untargeted and part of delayed mutations appears on not damaged DNA sites. ${ }^{7}$ There are now known to be many late expressed effects of exposure that cannot simply be explained on the basis of direct ionizing radiation DNA damages. Examples include genomic instability, bystander effects and adaptive responses. ${ }^{12}$ The bystander effects are defined as the induction of cellular damage in un irradiated cells, induced by irradiated cells in the surrounding area. ${ }^{8}$

Six mechanistic explanations for the phenomenon have been proposed. The most convincing explanation of radiation-induced genomic instability attributes it to an irreversible regulatory change in the dynamic interaction network of the cellular gene products, as a response to non-specific molecular damage ${ }^{3}$ Campa et al. underline the central role of cell-cell communication on non-targeted effects. ${ }^{13}$ According Averbeck the discovery of non-targeted and delayed radiation effects has challenged the classical paradigm of radiobiology. ${ }^{14}$ Watanabe assume that a radiation cancer-causing target is protein. ${ }^{15}$ Wright assume that radiation-induced genomic instability 
in vivo may not necessarily identify gnomically unstable somatic cells but the manifestation of responses to ongoing production of damaging signals generated by genotype-dependent mechanisms having properties in common with inflammatory processes. ${ }^{16}$ Furthermore, it is still not known what the initial target and early interactions in cells are that give rise to non-targeted responses in neighboring or descendant cells. ${ }^{10}$ Morgan believes that it is unlikely that these untargeted effects are directly induced by cellular irradiation. Instead, it is proposed that some as yet to be identified secreted factor can be produced by irradiated cells that can stimulate effects in no irradiated cells (death-inducing and bystander effects, clastogenic factors) and perpetuate genomic instability in the clonally expanded progeny of an irradiated cell. Furthermore, it must have the potential to stimulate cellular cytokines and/or reactive oxygen species ${ }^{17}$ Lyng et al. ${ }^{11}$ suggest that initiating events in the apoptotic cascade were induced in unit cells by a signal produced by irradiated cells and that this signal can still be produced in the progeny of irradiated cell. ${ }^{11}$

Moreover, it is concluded that only a third of the variation in cancer risk among tissues is attributable to environmental factors or inherited predispositions. The majority is due to "bad luck," that is, random mutations arising during DNA replication in normal, noncancerous stem cells. ${ }^{18}$ The conventional paradigm relates the reason of mutations exclusively to sporadic errors of DNA polymerases. ${ }^{19-23}$ (a more detailed review, see in ref.) ${ }^{24}$ The reasons of mutation origination are explained by the so-called "A-rule". ${ }^{22,25}$ It is assumed that DNA polymerases insert non-complementary bases opposite the damages. ${ }^{19,22}$ As part of the polymerase model mechanisms of the targeted, ${ }^{26,27}$ and untargeted ${ }^{19,20,28-33}$ base substitution mutations have been proposed. The mutations that result from incorrect bases are often targeted; that is, they occur at the same position as the photoproduct. ${ }^{26,27}$ Sometimes mutations are formed in the vicinity of damage, a process that is termed untargeted mutagenesis[19, 20, 28-33].Untargeted mutations currently called mutations appearing on so-called "undamaged" DNA sites. ${ }^{19,20,28-36}$ Untargeted mutagenesis requires the same proteins that are required for translesion synthesis. ${ }^{34}$ Untargeted mutagenesis occurs at SOS replication and error-prone DNA synthesis. ${ }^{19}$ Untargeted mutagenesis is characterized by a high rate of education of transversions..$^{19,34,36}$ It is assumed that untargeted base substitution mutations formed on undamaged DNA sites in result in random errors of DNA polymerases. . $^{1920,28-32,37-39}$

Many specialized DNA polymerases can lead translesion synthesis opposite of cyclobutane pyrimidine dimers ${ }^{23,31,35,40-44}$ and participate in the formation of untargeted mutations. For example, the DNA polymerase pol $\theta$ is processivity polymerase, which implies that it can strongly regulated to avoid mutagenesis. ${ }^{41}$ Error-prone polymerases $\mathrm{V}$ Escherichia coli (Pol V) and polymerase IV (Pol IV) are responsible for SOS-induced untargeted mutations. ${ }^{23,35,42}$ DNA polymerase IV causes untargeted and the targeted SOS mutagenesis., ${ }^{31,43}$ It can produce of the mutation in the vicinity of the damage those results in untargeted mutagenesis. ${ }^{19}$

In recent decades, the main efforts were focused on experimental determination and computer modeling of the structure of DNA polymerases and the mechanisms of nucleotide incorporation in the active sites of polymerases. ${ }^{45-56}$ Structural data are obtained for the mechanisms of the targeted and untargeted mutagenesis formation under the translesion synthesis via cyclobutane pyrimidine dimers. ${ }^{57-59}$ The role of the polymerases in cancer is investigated. ${ }^{59,60}$ However, despite the obvious advances in the study of the structure and functions of polymerases $19,20,37,39-41,45-55$ the modern theory of mutagenesis, based on polymerase paradigm, cannot fully explain many phenomena of mutagenesis. These include the reasons for the formation of hot and cold spots of ultraviolet mutagenesis. ${ }^{61,62}$ Much of it is not clear in the nature and mechanisms of formation of delayed mutations. ${ }^{63-66}$ It is not entirely clear mechanism for the formation of complex mutations. ${ }^{67,68}$ It is not clear why some cyclobutane pyrimidine dimers do not cause mutations, while others, seemingly the exact cause of transition or transversion mutations, or the just the same cyclobutane pyrimidine dimers cause frame shift mutations. The mechanism of formation the targeted frame shift mutations does not clear. ${ }^{69-73}$ Even the mechanisms of formation of the targeted base substitution mutations are not entirely clear. It is not clear why in some cases there are transitions, while in others cases there are, for example, homologous transversions, although it would seem that cause their cis-syn cyclobutane pyrimidine dimers exactly the same. It is not entirely clear how the mutations occur in the repair, such as excision repair or postreplicative repair. ${ }^{74,75}$

There remains much uncertainty on the issue of the nature and mechanisms of formation of untargeted mutations. It is not entirely clear why mutations occur on some "not damaged" sites of DNA. What's the difference between these sites from those on that do not appear untargeted mutation? As part of the polymerase model answer is no different. But is it? It is not clear why sometimes there are untargeted base substitution mutations, and, in other cases, untargeted frame shift mutation frame shift. When there are untargeted base substitution mutations it is not clear why in some cases appear untargeted transitions, in other cases appear untargeted transversions. There is no model explaining the mechanisms of untargeted complex mutations. And, of course, it is not as clear as may appear untargeted delayed mutations. It is known that untargeted and delayed mutations are a major manifestation of genomic instability. ${ }^{76}$ Instability of genome is the main cause of cancer. ${ }^{77}$ It is not clear why, in the genomic instability that leads to cancer, increases dramatically the number of untargeted and delayed mutations. In other words, the evidence suggests that the nature and mechanisms formation of untargeted mutations, genomic instability and cancer cannot be completely understood. Therefore, it is important to examine the nature and mechanisms of untargeted mutations in more detail.

I have attempted to construct a polymerase-tautomeric model for UV-induced mutagenesis, ${ }^{24,78-99}$ based on idea by Watson and Crick $^{77}$ that changes in tautomeric state are possible for DNA bases. It is proposed a mechanism for changes in the tautomeric state of base pairs under ultraviolet irradiation of DNA. ${ }^{79-82}$ It was assumed that the tautomeric state of the constituent bases may change during the formation of cyclobutane pyrimidine dimers. ${ }^{80-82}$ Five new rare tautomeric conformations of the adenine and thymine, ${ }^{81,82}$ they shown on Figure 1, and seven of the cytosine and guanine. ${ }^{80,83}$ Such rare tautomeric forms of DNA bases are stable when they are parts of the Cis-syn cyclobutane pyrimidine dimers and they are stable under DNA synthesis. ${ }^{81-84}$

It is proposed a polymerase-tautomeric model for the mechanisms of targeted base substitution mutations formation during error-prone or SOS synthesis of DNA containing Cis-syn cyclobutane pyrimidine dimers ${ }^{24,84-87,98}$ It is developed a polymerase-tautomeric model for targeted frame shift mutations, insertions ${ }^{88,89,98}$ and deletions ${ }^{90,91,98}$ caused by Cis-syn cyclobutane thymine dimers. It is proposed a polymerase-tautomeric model for the mechanisms of targeted complex insertions $\mathrm{s}^{92,98}$ and a polymerase-tautomeric model for the mechanisms of hot and cold spots of ultraviolet mutagenesis. ${ }^{93}$ It is proposed a 
polymerase-tautomeric model for the mechanisms of targeted delayed base substitution mutations caused by Cis-syn cyclobutane thymine dimers. ${ }^{97}$ Polymerase-tautomeric model for untargeted substitution mutations formation when DNA molecule contains Cis-syn cyclobutane thymine dimers also have been developed. ${ }^{94-96}$ However, preliminary works on untargeted mutagenesis ${ }^{94,95}$ relied on a number of hypotheses, from which in the future, under the study of the nature of the targeted mutagenesis I refused. ${ }^{84}$

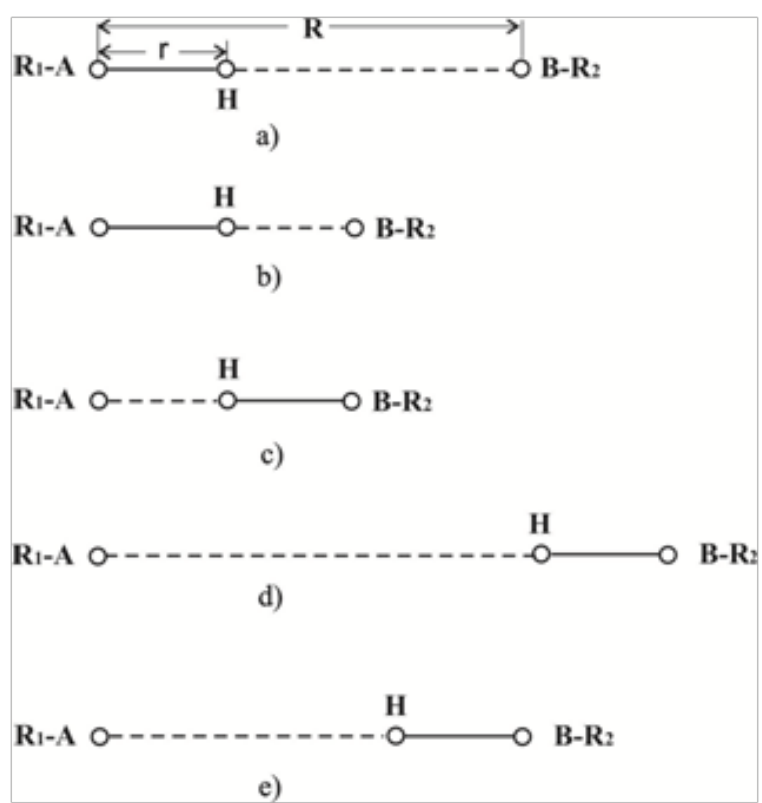

Figure I Diagrammatic representation of hydrogen bond between molecules $R_{1}-A$ and $B-R_{2}$

a) r-length of a valence bond between $A$ and atom of hydrogen $H$. R - length of hydrogen bond. b) the molecules bound by the hydrogen bond were pulled together so, that the atom of hydrogen is almost at the center between the molecules $\mathrm{c}$ ) the atom $\mathrm{H}$ has formed the same strong bond with $\mathrm{BR}_{2}$ as with $R_{1} A$ d) hydrogen bond has got longer. $H$ is connected by a valence bond with $\mathrm{BR}_{2}$ e) length of $\mathrm{H}$-bond was normalized, the atom of hydrogen now is connected. by a strong valence bond, to a molecule $B R_{2}$.

In order to understand how untargeted mutations are formed, it is necessary to understand how DNA damages are formed, which can be a source of untargeted mutations. For this, first, it is necessary to examine the processes by absorption of excitation energy in the DNA molecule. Secondly, we must look to which the chemical changes of DNA structure it will lead. Thirdly, it is necessary to understand the conditions under which the damages of DNA will be stable. Fourthly, to explore how these changes in the DNA can result in mutations under the replication and repair. In the first place I'll look at how the tautomeric state of bases DNA may change under UV light.

\section{Mechanism of alteration of tautomeric state of dna bases under irradiated of double stranded dna by ultraviolet light}

It is developed a model of the mechanism changes of the tautomeric states of the base pairs of DNA. It has been proved in detail for the case when the DNA molecule is irradiated with ultraviolet light. ${ }^{79-83,98,99}$ After irradiation of DNA by ultraviolet light excitation energy ultimately localized on one of the bases. This results in the excitation of electronic-vibration states. ${ }^{100}$ For a triplet level excitation, the most probable process for relaxation involves the transformation of energy to oscillations of the neighboring atoms, ${ }^{101}$ in other words in a heat. No radiative deexcitation in DNA molecules occurs in a small volume of 3-5 bases pairs. ${ }^{102,103}$ This results in a strong "local heatingup", followed by initiation of normal oscillations of the bases. After several oscillations, taking $\sim 10^{-14}-10^{-12} \mathrm{sec},{ }^{104-108}$ the vibratory system will reach equilibrium. The oscillations of atoms will cause changes in the distances between the paired bases, in other words, in the lengths of H-bonds. Hydrogen bond is called such a bond when there is a hydrogen atom between the two electronegative atoms. The shapes of the potential curves for the protons of all three $\mathrm{H}$-bonds of Watson and Crick's G:C base pair for several lengths of H-bonds were calculated in ref. ${ }^{109,110}$ Calculations were based on semi-empirical potential function, capable of adequately describe hydrogen bonds with lengths different from the equilibrium lengths. ${ }^{111}$ It turned out that a decrease in the length of a $\mathrm{H}$-bond by $0.02 \mathrm{~nm}$ from the equilibrium transforms the proton potential into a single-well. With an increase in H-bond length, the second minimum becomes more and more obvious. The dynamics of the changes in the shape of proton potential for a wide spectrum of $\mathrm{H}$-bond lengths were calculated. ${ }^{110}$ Hydrogen bonds that are formed between the DNA bases have the following property. They are characterized by a strong valence bond with one of the partner atoms in the H-bond, and a weak bond with the other (Figure 1a). When the H-bond length (R) of a valence bond changes, the length (r) changes very little. But distance from the hydrogen to the second atom (R-r) varies considerably. ${ }^{111}$ Let hydrogen bond length $(\mathrm{R})$ reduced so that hydrogen was almost in the center of the hydrogen bond (Figure 1b). In this case, it forms a strong bond with the two electronegative atoms (Figure 1c). Therefore, when the hydrogen bond begins to lengthen, hydrogen may remain in the new position (Figure 1d). After that hydrogen bond length is increased a hydrogen atom will be in a local minimum. ${ }^{104,106,110}$ The assumption of favorable conformations is possible, as the lifetime of a triplet state is $\sim 10^{-6} \mathrm{sec} .{ }^{101}$ The lifetime of the excited H-bond is $\sim 4 \times 10^{-9}$ sec. ${ }^{112,113}$ In the same time the characteristic periods of atomic oscillations are $10^{-14}-10^{-12} \mathrm{sec} .^{104-108}$ Therefore, there will be not more than several $10 \mathrm{~s}$ of oscillations up to 100 oscillations that influence the length of the H-bond. This results in a time of $\sim 10^{-10} \mathrm{sec}$ for any one conformation which is much less than the lifetime of the triplet state. Thus, the hydrogen atom will remain with their partner on hydrogen bond (Figure 1e). The calculations ${ }^{104-108,110,112,113}$ semi empirical potential function for protons of hydrogen bonds was used, it was developed by Tolpygo \& Grebneva. ${ }^{109}$ The proposed model is in a good agreement with the results obtained by other authors. ${ }^{114-116}$ The transitions of the protons in hydrogen bonds are very common. Proton transitions in H-bonds occur in acids and bases, in crystals, proteins, molecular membranes, enzymes, and in other systems. ${ }^{117}$

In a canonical DNA molecule, conformational fluctuations of different DNA sites result in different metastable states. ${ }^{118,119}$ The exposure of bases from a double spiral to the solution is known as "opening" or "melting" of Watson and Crick's pairs. In this case, the hydrogen bonds between DNA bases are broken. ${ }^{118}$ Metastable states developing with incomplete opening of the pair and with partial conservation of $\mathrm{H}$-bonds and with the amine group free from $\mathrm{H}$-bond are called semi open metastable states. ${ }^{118}$ There exist several models of semi open metastable states. ${ }^{118,119}$ In my opinion, the model developed by Hovorun ${ }^{119}$ is well-grounded; it explains a number of phenomena and is confirmed by experimental data. It is rather probable that the process of tautomeric state change goes in two stages. At the first stage, the metastable semi open DNA states predicted in $\operatorname{Ref}^{119}$ are formed. At the second stage, the formed rare metastable tautomeric 
states transform into the stable ones. Allowance the predicted ${ }^{119}$ a metastable state leading to that rare tautomeric forms of thymine $\mathrm{T}^{*}{ }_{4}$ and $\mathrm{T}_{5}$ and rare tautomeric forms of adenine $\mathrm{A}_{4}{ }_{4}$ and $\mathrm{A}_{5}{ }_{5}$ (Figure $2)^{82,83}$ can be formed.

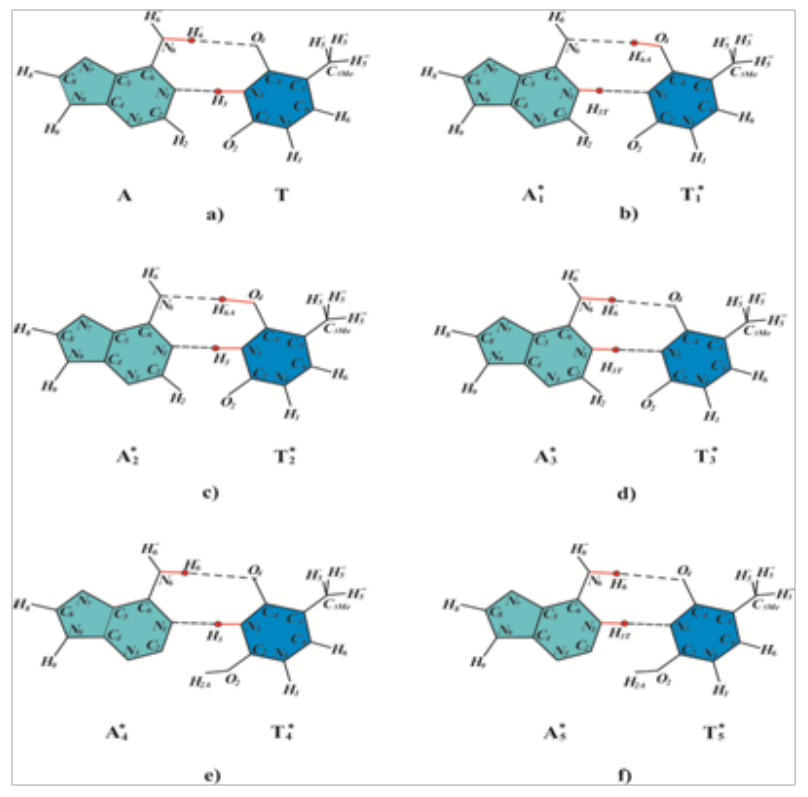

Figure 2 Possible rare tautomeric state of thymine and adenine:

a) adenine $(A)$ and thymine $(T)$ in canonical tautomeric forms.

b) f) molecules of adenine $\left(A_{i}^{*}\right)$ and molecules of thymine $\left(T_{i}^{*}\right)$ in rare tautomeric forms, $i=1 \div 5$.

Double-stranded DNA contains the guanine-cytosine and adeninethymine base pairs. In these pairs bases are interconnected by hydrogen bonds, and they are located in different strands. As a result of changes in the lengths of the hydrogen bonds caused by the strong thermal vibrations a hydrogen atom can remain with his partner in a hydrogen bond. If such an event occurs, it means that the tautomeric states of DNA bases are changed. Thus tautomeric states always change in both bases bonded by hydrogen bond because hydrogen is separated from the one base and joined to another base of the pairs. ${ }^{80-82}$ As shown in the quantum-mechanical calculations, in all cases (except for one) hydrogen atoms are returned to the original position. ${ }^{120-122}$ In other words, the bases are usually returned to their canonical tautomeric states.

\section{The reasons for the stability of the rare tautomeric forms of DNA bases}

Let us see under what conditions the rare tautomeric forms of the DNA bases will be saved. The rare tautomeric forms of bases are stable at Cis-syn cyclobutane pyrimidine dimers formation and in DNA synthesis. ${ }^{82,84}$ If under the formation of the Cis-syn cyclobutane pyrimidine dimer tautomeric states of its constituent bases has changed, such rare tautomeric states will be stable. ${ }^{82,84}$ The rare tautomeric forms of bases are stable because, at Cis-syn cyclobutane pyrimidine dimers formation, the DNA strand is bent and the hydrogen bonds between the bases are significantly weakened or are broken. ${ }^{123-126}$ When the hydrogen bond becomes weaker it becomes longer. In this case, there is a second minimum and the second minimum deepens. ${ }^{105,106,110}$ Therefore, if under the thermal relaxation of the excitation energy the hydrogen atom will go to partner for the hydrogen bond, the new tautomeric state will be stable even with a small elongation of the hydrogen bond. And, of course, such a rare tautomeric state will be stable at breaks of hydrogen bonds. That is why the hydrogen atoms between the bases located in different DNA strands, which form a pair, will not be able to return to their former partners in hydrogen bonds, and will remain in the new provisions. This means that there is change of tautomeric states of bases, and it will be stable. ${ }^{80-84}$

But the bases in rare tautomeric forms are stable and when they are near photodimers. ${ }^{94-96}$ DNA strand containing cyclobutane dimers, especially if there are several cyclobutane dimers located close to each other so DNA strand is bent that it forms a loop, so that the hydrogen bonds between the bases located adjacent to photodimers also are torn. Hydrogen atoms cannot return to their original position, because they are no longer bound by hydrogen bonds. Therefore, if in a small neighborhood from a cyclobutane dimer the bases in rare tautomeric form are formed, such a rare tautomeric states will be stable. An important step in improving the accuracy of DNA synthesis is the stage of identification of nucleotides and nucleotide pairs. Increased ability to distinguish nucleotides polymerases achieved in particular by removing water from active sites of the enzymes. ${ }^{127,128}$ The molecule of enzyme - is usually a very large molecule and it shuts substrate molecule that falls in the active site of the enzyme, from the influence the environment. Lack of water in the active sites of polymerases preserves tautomeric states bases involved in the synthesis, when the DNA molecule is in single stranded form.

It is possible that the DNA molecule will be in single stranded form when DNA molecule is replicated. Let us estimate, what is the probability that this bases, are in rare tautomeric forms, pass into canonical tautomeric states due to contact with water molecules. Experimental evidence indicates that the lifetime of "free" guanine, i.e. the time it takes until it interacts with a water molecule, ranges from 0.1 to $10 \mathrm{sec}$, and can be as long as $1,000 \mathrm{sec} .{ }^{129}$ And we are talking about guanine molecules in an aqueous medium. For a guanine, the incoming DNA strand, it is much more. Different DNA polymerases synthesize nucleotides at a rate of $10 / \mathrm{sec}$ to $1000 / \mathrm{sec} .{ }^{19-21,23}$ Suppose that during the synthesis of the DNA strand at a time will be in single stranded form. The time at which it will not be protected by the enzymes is determined by the speed of the enzymes. For DNA polymerase $\mathrm{V}$, having the lowest rate of synthesis it is not more than 0.1 seconds. Since the time required for bases came into contact with the water molecule and has changed they tautomeric state, more than 0.1 seconds, we see that the probability of such a process is quite small. ${ }^{84}$ The results of studies on the structure of the active centers of polymerases show that the bases in rare tautomeric forms may exist in the active centers of polymerases. ${ }^{130-135}$ More details on this issue is set out in $\operatorname{ref}^{98}$

An important question is, how often can form bases in the rare tautomeric forms. As shown experimentally in studies of hot and cold spots ultraviolet mutagenesis, cyclobutane pyrimidine dimers appear very often. ${ }^{61,62}$ Analysis of the nucleotide sequences on which cyclobutane pyrimidine dimers are appeared, which led to the formation of targeted base substitution mutations, reveals that such cyclobutane pyrimidine dimers, are often at a distance of one, two, three or four nucleotides apart ${ }^{61}$ (Figure 3). Source of damages during the formation of cyclobutane dimers and changes of tautomeric states of bases is the same. It has strong forced oscillations with non-radiative relaxation 
of the excitation energy from the triplet energy level..$^{82}$ To change the tautomeric state of DNA bases is needed much less of energy than for the cyclobutane pyrimidine dimers formation. Consequently, rare tautomeric forms of bases may occur more frequently than cyclobutane dimers are formed. Thus, in principle, all the bases of DNA can change its tautomeric states. Of course, we must note that thymines and adenines are much less likely to change their tautomeric states than cytosines and guanines. ${ }^{136}$ The critical question is whether these rare tautomeric states are stable. And it is entirely dependent on whether cyclobutane dimers or other damages are formed around them, and whether the DNA strand is is bent opposite of this damage. If not, then all of the hydrogen atoms return to their original positions (except one rare tautomeric form of guanine and cytosine) $)^{120-122}$ and rare tautomeric states of DNA bases are not formed. If next to the bases in rare tautomeric forms will be cyclobutane dimers is every reason to remain in his rare tautomeric forms. This is because during the formation of cyclobutane pyrimidine dimer DNA strand is curved, loop occurs, hydrogen bonds are broken. ${ }^{123-126}$ Hydrogen atoms are unable to return to their former states; they are no longer associated with their partners via hydrogen bonds. ${ }^{82}$

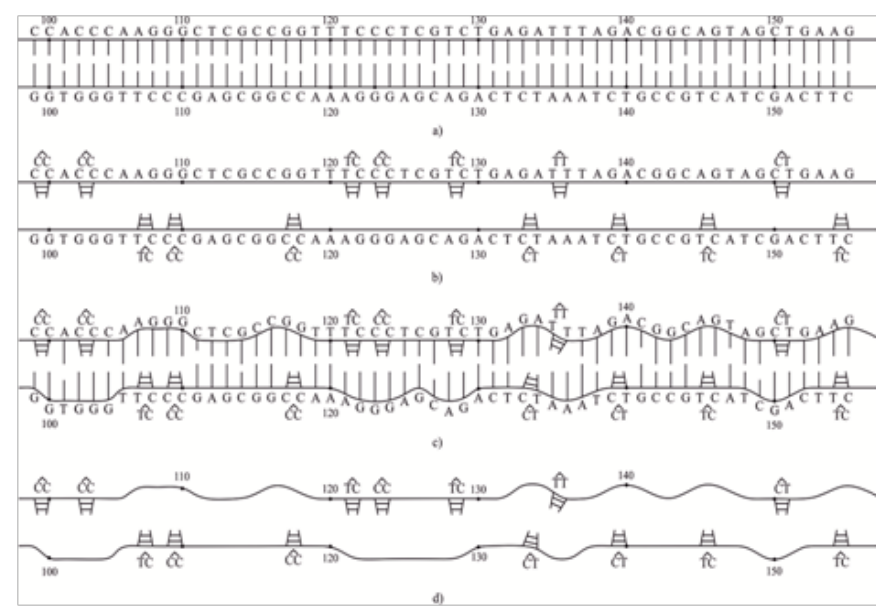

Figure 3 Formation of the loops opposite cyclobutane pyrimidine dimers at the supF site of DNA on which in Ref. ${ }^{60,61}$ it was found hot and cold spots of ultraviolet mutagenesis:

a) Scheme of the DNA site supF which is irradiated with ultraviolet light.

b) Cyclobutane pyrimidine dimers are formed at the supF DNA site. They are marked caps.

c) Bulges (loops) are formed opposite the cyclobutane pyrimidine dimers.

Figure 3 shows a site of DNA on that is obtained hot and cold spots ultraviolet mutagenesis. ${ }^{61,62}$ The diagram shows that if the hydrogen bonds between the bases forming part of cyclobutane pyrimidine dimers are extended, the loops formed in the vicinity of these dimers. And, therefore, all rare tautomeric forms of the bases will be sustainable.

The mechanism of rare tautomeric forms of DNA bases under UV-irradiation is valid for any mutagens

It is easy to see that the mechanism of formation of rare tautomeric forms of paired bases of DNA depends only on the properties of hydrogen bonds and properties of DNA molecules. Consequently, it will be true under the action of a DNA molecule of any mutagens. Since the mutagen causes any damage to the DNA molecule, it exhibits excitation energy. This energy is absorbed by one of the DNA bases this lead to the excitation of the electron-vibrational states. ${ }^{100}$ At the thermal relaxation of the excitation energy it will cause fluctuations in the lengths of the hydrogen bonds between paired bases. Change in lengths of the hydrogen bonds can lead to changes of tautomeric states of DNA bases. Under certain conditions, the formed rare tautomeric forms of DNA bases will be stable.

Such a mechanism is certainly possible under irradiation of ionizing radiation of DNA molecule. The action of the free radicals, mainly singlet oxygen leads to spontaneous mutagenesis. ${ }^{137,138}$ In these cases, as is known, a large number of damages of DNA bases and of sugar-phosphate backbone are formed. ${ }^{137,138}$ Most often, they do not lead to targeted mutations but to the cell death. ${ }^{137,138}$ But, of course, in the small vicinity of DNA damages the bases in rare tautomeric forms can be formed. If the damages are such that the hydrogen bonds between the bases are broken or at least are lengthened, the given rare tautomeric forms of the bases will remain stable for a long time.

The mechanisms of untargeted base substitution mutations formation during error-prone and SOS replication of double-stranded DNA containing in both DNA strands closely spaced Cis-syn cyclobutane thymine dimers

Targeted and untargeted mutations formed when modified DNA ${ }^{139}$ or specialized DNA polymerases are involved in the synthesis of DNA. ${ }^{35,140-148}$ Specialized DNA polymerases may make errors that give rise to mutations. ${ }^{71,72}$ In addition, the translesion synthesis can be conducted using constitutive DNA polymerases. ${ }^{148-150}$ Under unmistakable synthesis DNA polymerase, made a mistake, dissociates from the primer. Most erroneously incorporated nucleotides are removed during DNA replication by $3^{\prime} \rightarrow 5^{\prime}$ exonucleases. ${ }^{151,152}$ The sliding clamp mechanism presses the DNA polymerase against the template and prevents the $3^{\prime} 5^{\prime}$-exonuclease from removing the "improper" base. ${ }^{148-150}$ In this case, the constitutive DNA polymerase synthesis becomes able to carry on a matrix containing cyclobutane dimers. Another consequence is the reduction of synthesis of accuracy, this can result in mutations. ${ }^{153}$

Translesion synthesis resulting in mutations occurs only when the template DNA contains damages that can stop DNA synthesis. In the case of irradiation of DNA by ultraviolet light, they are photodimers, namely cyclobutane pyrimidine dimers or (6-4) adducts. Therefore, if untargeted mutations are formed in the so-called undamaged DNA sites, necessarily in a small neighborhood of them should be photodimers. Otherwise translesion synthesis mechanisms just do not turn on, and DNA synthesis will be carried out error-free DNA polymerases. Specialized and modified DNA polymerases inserts opposite of cyclobutane pyrimidine dimers canonical bases capable of forming hydrogen bonds with bases in template DNA. ${ }^{84}$ Thus, the error-prone DNA synthesis is exactly the same as an unmistakable synthesis.

Let after irradiation with UV light of the DNA molecule in it the Cis-syn cyclobutane thymine dimers are formed $\mathrm{TT}, \mathrm{T} * \mathrm{~T}, \mathrm{~T} * \mathrm{~T}, \mathrm{~T} * \mathrm{~T}$, $\mathrm{T}_{4} * \mathrm{~T}$ and $\mathrm{T}_{5} * \mathrm{~T}$, whereTis canonical (Figure 2a), and $\mathrm{T}_{1} * \mathrm{~T}_{2} * \mathrm{~T}_{3} *$, $\mathrm{T}_{4} *$ and $\mathrm{T}_{5}{ }^{*}$ are rare tautomeric forms of thymine (Figure 2a-Figure $2 \mathrm{e}$, respectively). Under the formation of the Cis-syn cyclobutane thymine dimers tautomeric forms of thymine which are part of a cyclobutane thymine dimers, may change as shown in Figure 3. All 
of these tautomeric states of the bases will be stable.$^{80-82,84}$ During the formation of the Cis-syn cyclobutane pyrimidine dimers tautomeric state and changes of their constituent base there is a change in the tautomeric states of mated bases, i.e. in the purines. ${ }^{80-82,84}$ Let these Cis-syn cyclobutane thymine dimers appeared in both strands of DNA close to each other as shown in Figure 4a. Then, on both DNA strands opposite Cis-syn cyclobutane thymine dimers with bases in rare tautomeric forms, the adenine molecules $A_{1}{ }^{*}, A_{2}{ }^{*}, A_{3}{ }^{*}, A_{4}{ }^{*}, A_{5}{ }^{*}$ in rare tautomeric forms will be (Figure $4 \mathrm{a}$ ). The rare tautomeric states of DNA bases are shown in Figure 2. These rare tautomeric forms of the adenine molecules will be stable as adenine molecules in rare tautomeric forms are not far from cyclobutane dimers.

\begin{tabular}{|c|c|c|c|c|c|}
\hline$\widehat{\hat{P}_{\mathrm{i}}}$ & $\underline{\Delta:}$ & $\widehat{\mathrm{O}^{2}=}$ & $\Delta ;$ & r: & $\leq \approx$ \\
\hline \multirow[t]{2}{*}{ Ai } & र्: & A: & & i: & कि \\
\hline & & & a) & & \\
\hline \multirow{2}{*}{$\widehat{\mathrm{Tr}}$} & $\underline{\Delta:}$ & $\widehat{\mathrm{Tr}_{2}}$ & s: & Pr: & $\underline{1}$ \\
\hline & $\dot{T}$ & & & & $\ddot{T T}$ \\
\hline c & & $\mathbf{T}$ & & & \\
\hline \multirow[t]{2}{*}{ A: } & ति: & A; & Tr: & A; & भิT \\
\hline & & & b) & & \\
\hline \multirow[t]{2}{*}{$\widehat{\mathrm{Mr}}$} & $\underline{\underline{*}}$ & $\widehat{\mid r: ;}$ & $\underline{\alpha}:$ & $\mathrm{rr}$ & 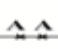 \\
\hline & $\dot{\mathbf{T}}$ & & & & $\dot{\mathbf{T} T}$ \\
\hline \multicolumn{2}{|l|}{$\hat{\Delta}$} & $\mathbf{T}$ & & & \\
\hline \multirow[t]{2}{*}{ si } & T: & A: & T: & A; & $\widehat{\text { Tि }}$ \\
\hline & & & e) & & \\
\hline \multirow[t]{2}{*}{$\widehat{\mathrm{Tr}_{i}}$} & $\underline{2}:$ & $\widehat{\mathrm{EF}_{2}}$ & $\underline{\alpha}:$ & Tr: & $\underline{\underline{1}}$ \\
\hline & $\vec{T}$ & & $\vec{T}$ & & $\vec{T}$ \\
\hline \multicolumn{2}{|l|}{$A(C)$} & $\mathbf{I}$ & & $\mathbf{I}$ & \\
\hline A: & रि: & A: & $\begin{array}{l}\text { (T): } \\
\text { d) }\end{array}$ & A; & कि \\
\hline
\end{tabular}

Figure 4 SOS or error-prone DNA synthesis of molecules containing cis-syn cyclobutane thymine dimers in both DNA strands:

a) DNA site containing the cis-syn cyclobutane thymine dimers.

b) Both strands of DNA are synthesized by specialized or modified DNA polymerases, opposite the adenine molecules in rare tautomeric forms $A_{1}{ }^{*}$ cytosine molecule is incorporated.

c) Both strands of DNA are synthesized by specialized or modified DNA polymerases, opposite adenine molecules in rare tautomeric forms $A_{\text {, }}$ * adenine molecule is incorporated.

d) Gaps in one nucleotide inserted correctly, opposite adenine molecule in the rare tautomeric form $A_{1}^{*}$ is incorporated molecules of cytosine or adenine.

If the Cis-syn cyclobutane thymine dimers are not removed, then this site of DNA is synthesized by DNA polymerases, capable of carrying out the SOS synthesis, or the error-prone synthesis. When there is SOS synthesis of bacteria's DNA synthesis occurs with the participation of a modified DNA polymerase III E. Coli using the mechanism of "sliding clamp" 139 or with the participation of a specialized DNA polymerases IV or VE. Coli. . $9,20,23,31,33,42-44^{-1}$ DNA polymerase pol $\mathrm{V}$ can proceed synthesis much further from damages. ${ }^{44}$ If there is translesion synthesis of mammals then DNA polymerases $\delta$ or $\varepsilon$ of mammals modified by "sliding clamp" the mechanism are involved ${ }^{148-150}$ or specialized DNA polymerase, such as Pol $\eta$, Pol $\zeta$, Pol кor Pol $\theta$ of mammals. ${ }^{35,41,143-147}$ Let's see what happens when opposite the DNA bases on the site shown in Figure $4 \mathrm{a}$, canonical bases are inserted by specialized or modified DNA polymerases. Cis-syn cyclobutane thymine dimers will result in the targeted mutations. ${ }^{84-86}$ In Figure 4, the targeted mutations I have not have represented.

In order to determine which of the canonical bases will be inserted by the modified or specialized DNA polymerase opposite adenines in rare tautomeric forms (Figure 2), consider the constraints on the formation of hydrogen bonds between the bases of the template DNA and the inserted bases. Since the $A_{1}{ }^{*}$ base (Figure $2 b$ ) is located in a small neighborhood of the Cis-syn cyclobutane thymine dimer $\mathrm{TT}_{4}^{*}$ (Figure 4a), a nucleotide opposite to it can be incorporated by DNA polymerase is able to lead the translesion synthesis, that is, or modified, or specialized DNA polymerase only. DNA polymerases insert canonical nucleotides that can form hydrogen bonds with the matrix bases $\mathrm{A}_{1}^{*}$ only. In the case of non-canonical base pairs wrong nucleotide is not deleted. ${ }^{84}$ The rare tautomer $\mathrm{A}_{1}^{*}$ (Figure $2 \mathrm{~b}$ ) cannot form hydrogen bonds with canonical molecule of thymine for steric reasons. But canonical tautomeric forms of cytosine can be incorporated opposite $\mathrm{A}_{1}$ * (Figure 5a) and canonical tautomeric forms of adenine can be incorporated opposite $\mathrm{A}_{1}$ * (Figure $5 \mathrm{~b}$ ). There is another version of events. However, if the $\mathrm{H}_{6}$ " hydrogen atom in $\mathrm{A}_{1}{ }^{*}$ will take the position that the hydrogen atom $\mathrm{H}_{6}$ ' of molecule of adenine in canonical form takes then adenine $\mathrm{A}_{1}{ }^{*}$ ' is formed. Molecule of adenine $\mathrm{A}_{1}{ }^{*}$ ' cannot form hydrogen bonds with any bases in canonical tautomeric forms. Let adenine molecule $\mathrm{A}_{2}{ }^{*}$, which is in rare tautomeric form corresponding to Figure $2 \mathrm{c}$, is located in a small neighborhood of a cyclobutane dimer (Figure 4a). In the synthesis of the DNA site using specialized or modified DNA polymerase $\mathrm{A}_{2}{ }^{*}$ adenine molecule can form hydrogen bonds with canonical thymine (Figure 5c). We cannot exclude the fact that the hydrogen atom $\mathrm{H}_{6}$ " of molecule $\mathrm{A}_{2}{ }^{*}$ will change its position and will be located as the atom $\mathrm{H}_{6}^{\prime}$ in a canonical molecule of adenine. In this case two hydrogen bonds between adenine $\mathrm{A}_{2}{ }^{*}$ ' and canonical thymine can form too.

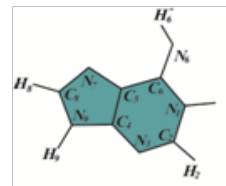

$\mathbf{A}_{\mathrm{i}}$

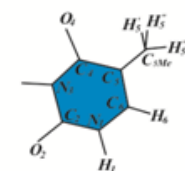

$\mathbf{T}$

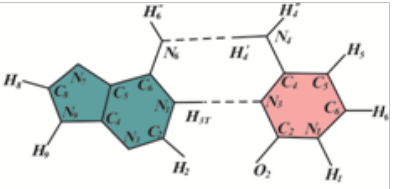

$\mathbf{A}_{i}^{*}$

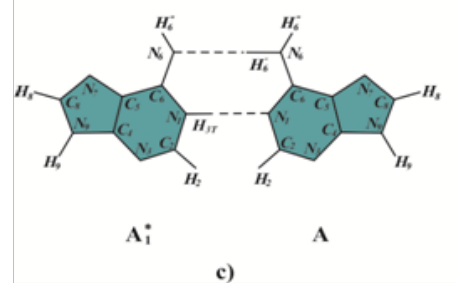

Figure 5 Possible base pairs of adenine molecules in rare tautomeric forms $A_{1}^{*}$ with bases in the canonical tautomeric forms: a) adenine in rare tautomeric form $A_{1}^{*}$ cannot form hydrogen bonds with canonical thymine. b) Pair of adenine molecules $A^{*}$ with canonical cytosine. c) Pair of adenine molecules $A_{1}^{*}$ with canonical adenine.

Molecules of adenine in rare tautomeric forms $\mathrm{A}_{3}^{*}$ (Figure 2d) and $\mathrm{A}_{5}^{*}$ (Figure $2 \mathrm{f}$ ) cannot form hydrogen bonds with any bases in canonical tautomeric forms. Molecule of adenine $\mathrm{A}_{4}{ }^{*}$ in rare tautomeric forms (Figure 2e) can form hydrogen bonds with canonical thymine (Figure 5d). Opposite Cis-syn cyclobutane thymine dimers

Citation: Grebneva HA.A polymerase tautomeric model for radiation induced bystander effects: a model for untargeted base substitution mutagenesis during error prone and SOS replication of double stranded DNA containing thymine and adenine in rare tautomeric forms. Int J Mol Biol Open Access. 20I7;2(2):63-74. DOI: I0.I5406/ijmboa.2017.02.000I8 
with bases in canonical tautomeric form molecules of the adenine will be in canonical tautomeric form. During DNA synthesis by specialized or modified DNA polymerase inserted canonical bases may form hydrogen bonds with canonical thymines that are part of the Cis-syn cyclobutane thymine dimers. Similarly, opposite of the thymine molecules in canonical tautomeric form that are included in the Cis-syn cyclobutane dimers $\mathrm{TT}_{1} *, \mathrm{TT}_{2} *, \mathrm{TT}_{3} *, \mathrm{TT}_{4} *$ and $\mathrm{TT}_{5} *$ adenine molecules will be in the canonical tautomeric form.

Let's analyze error-prone and SOS synthesis of the DNA site shown in Figure 4, which takes place by means of specialized or modified DNA polymerases. As we have seen, opposite the adenine $\mathrm{A}_{1}^{*}$ DNA polymerases cannot insert canonical thymine so that between them may be formed hydrogen bonds. This means that the canonical base pair and $\mathrm{A}_{1}{ }^{*}$ cannot be formed and this inevitably lead to mutations. If cytosine will be inserted the $\mathrm{A}_{1}{ }_{-} \mathrm{C}$ pair will be form (Figure $4 \mathrm{~b}$ ). Consequently, in this case, a transition A-T $\rightarrow \mathrm{G}-\mathrm{C}$ appears. But opposite $\mathrm{A}_{1}^{*}$ may be inserted molecule of adenine then the pair $A_{1}{ }^{*}-A$ is formed (Figure $4 c$ ). (Figure $4 \mathrm{~B}$ ). If opposite $A_{1}{ }^{*}$ canonical adenine will be inserted it would mean the formation of homologous transversion A-T $\rightarrow \mathrm{T}-\mathrm{A}$. As is known, some specialized DNA-polymerase, for example DNA polymerase V, provide a high percentage transversions. ${ }^{51}$

Opposite the molecules adenine $\mathrm{A}_{3} *$ and $\mathrm{A}_{5} *$ it is impossible to incorporate any of the canonical bases, so that between them and the adenines in rare tautomeric forms hydrogen bonds are formed. The result will be a gaps in a single nucleotide, which is likely, in the future will be inserted correctly. Opposite $\mathrm{A}_{2} *$ and $\mathrm{A}_{4} *$ can insert the molecule thymine and then the mutations do not appear. Therefore, in this case to untargeted base substitutions mutations can lead only adenine molecules $\mathrm{A}_{1}$ *

The mechanisms of untargeted base substitution mutations formation during error-prone and SOS replication of double-stranded DNA sites containing in both DNA strands molecules of thymine and adenine in rare tautomeric forms closely spaced from cyclobutane pyrimidine dimers

Let us consider a site of DNA, on which in a small neighborhood of cyclobutane pyrimidine dimers with bases in the canonical tautomeric forms pairs base of adenine-thymine in rare tautomeric forms are formed. Let not far from cyclobutane dimers pairs are appeared $\mathrm{T}_{1}{ }^{*}-\mathrm{A}_{1}{ }^{*}, \mathrm{~T}_{2} *-\mathrm{A}_{2}{ }^{*}, \mathrm{~T}_{3}{ }^{*}-\mathrm{A}_{3} *, \mathrm{~T}_{4}{ }^{*}-\mathrm{A}_{4}{ }^{*}$ and $\mathrm{T}_{5} *-\mathrm{A}_{5} *$ as it shown in Figure 6a. Bases in rare tautomeric forms are stable. Let's see which the canonical DNA bases can be inserted opposite the molecules adenine and thymine in rare tautomeric forms, illustrated in Figure 2. Structural analysis of the insertion of the bases, made in ref. ${ }^{84}$ in the study of mechanisms of targeted base substitutions mutations, showed that opposite the molecule of thymine $\mathrm{T}_{1}{ }^{*}$ is impossible to incorporate a molecule of adenine in the canonical tautomeric form so that between them hydrogen bonds are formed. But molecules of guanine or thymine can be inserted. Opposite molecule of thymine in rare tautomeric form $\mathrm{T}_{2} *$ cannot any canonic bases so that between them hydrogen bonds are formed. ${ }^{84}$ Opposite the thymine in rare tautomeric forms $\mathrm{T}_{3} *$ molecule of the adenine can be inserted. ${ }^{97,98}$ The rare $\mathrm{T}_{5}{ }^{*}$ and $\mathrm{T}_{4} *$ tautomers cannot form hydrogen bonds with canonical tautomer of adenine for steric reasons. Canonical tautomeric forms of cytosine and thymine can be incorporated opposite $\mathrm{T}_{5} *$. The rare $\mathrm{T}_{4} *$ tautomer is capable of forming hydrogen bonds with cytosine. ${ }^{84}$ As shown above adenine $\mathrm{A}_{1} *$ does not form hydrogen bonds with canonical tautomer of thymine (Figure 5a), but $\mathrm{A}_{1}{ }^{*}$ can form hydrogen bonds with canonical tautomer of cytosine (Figure $5 \mathrm{~b}$ ) and with canonical tautomer of adenine (Figure $5 \mathrm{c}$ ). The rare $\mathrm{A}_{3} *$ and $\mathrm{A}_{5}{ }^{*}$ tautomers do not form hydrogen bonds with canonical tautomers of DNA bases. The rare $\mathrm{A}_{2} *$ and $\mathrm{A}_{4}^{*}$ tautomers of adenine can form hydrogen bonds with thymine.

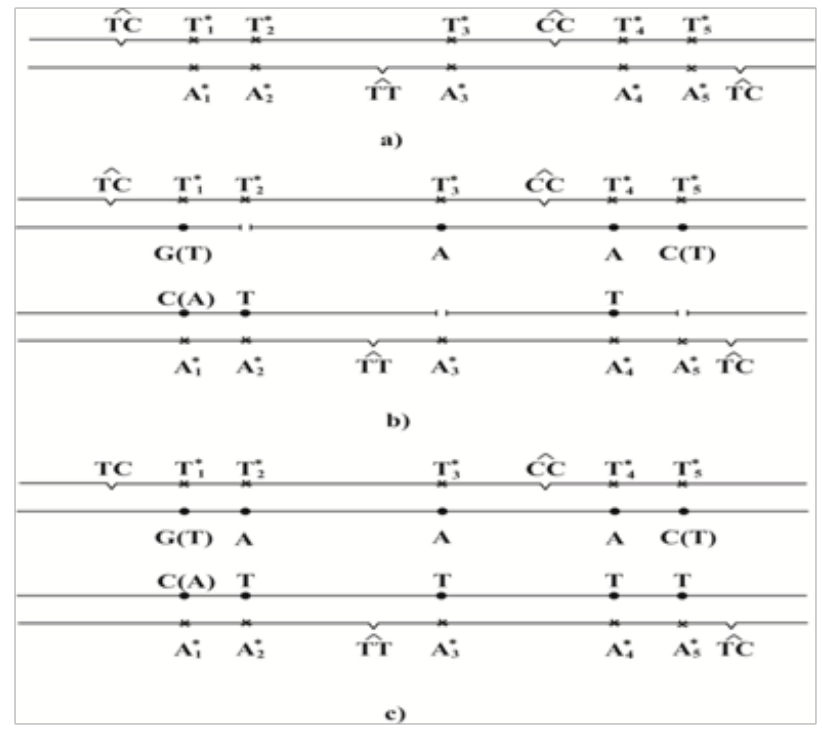

Figure 6 SOS or error-prone synthesis of DNA molecules containing the base pairs adenine - thymine in rare tautomeric forms in the small vicinities of any cyclobutane dimers:

a) Site of DNA containing molecules of adenine and thymine in rare tautomeric forms in the small vicinities of any cyclobutane dimers.

b) Both strands of DNA are synthesized by specialized or modified DNA polymerases; opposite the molecules of adenine in rare tautomeric form $A_{1}$ * are inserted canonic molecule of cytosine or adenine. opposite the molecules of thymine in rare tautomeric form $T_{1}^{*}$ are inserted canonic molecule of guanine or thymine; opposite the molecules of thymine in rare tautomeric form $\mathrm{T}_{5} *$ are inserted canonic molecule of cytosine or thymine.

c) Gaps in one nucleotide are inserted correctly; opposite the $A_{1}^{*}$ are inserted canonic molecule of cytosine or adenine; opposite the $\mathrm{T}_{1}^{*}$ are inserted canonic molecule of guanine or thymine. Opposite the $\mathrm{T}_{5} *$ are inserted canonic molecule of cytosine or thymine.

Let us the site of DNA shown in Figure 6a is synthesized as a result of error-prone or SOS synthesis. This means that, firstly, these damage of DNA are not removed, and secondly, the site will be inserted by specialized or modified DNA polymerases. Canonical tautomeric forms of guanine or thymine can be incorporated opposite $\mathrm{T}_{1}{ }^{*}$.In this case, $\mathrm{A}-\mathrm{T} \rightarrow \mathrm{G}-\mathrm{C}$ transition or $\mathrm{A}-\mathrm{T} \rightarrow \mathrm{T}-\mathrm{A}$ homologous transversion will result (Figure 6b). Thus, if the near cyclobutane dimers the rare $\mathrm{T}_{1} *$ tautomer is formed and, if it proved to be stable, then the errorprone or SOS DNA synthesis, it will inevitably lead to untargeted base substitution mutations, transitions or homologous transversions. But the rare $\mathrm{T}_{1} *$ tautomer cannot result in $\mathrm{A}-\mathrm{T} \rightarrow \mathrm{C}$-Gtransversions.

The rare $\mathrm{T}_{2} *$ tautomer cannot form hydrogen bonds with any canonic tautomers of DNA bases for steric reasons. Therefore, likely DNA synthesis will result in a one-nucleotide gap (Figure 6b), which will be further incorporated by unmistakable manner (Figure 6c). Since opposite the thymine in rare tautomeric forms $\mathrm{T}_{3}{ }^{*}$ molecule of adenine can be inserted, it is likely it will not result in mutations. 
Molecules of the thymine in rare tautomeric form $\mathrm{T}_{4}^{*}$ may result in transversion $\mathrm{A}-\mathrm{T} \rightarrow \mathrm{C}-\mathrm{G}$ only. Rare $\mathrm{T}_{5}{ }^{*}$ tautomer is possible to incorporate molecules of cytosine or thymine84 they can result in transversion $\mathrm{A}-\mathrm{T} \rightarrow \mathrm{C}-\mathrm{G}$ or homologous transversions $\mathrm{A}-\mathrm{T} \rightarrow \mathrm{T}-\mathrm{A}$ only (Figure 6b). Just like in the previous case, $\mathrm{A}_{1}$ * can result in $\mathrm{A}-\mathrm{T} \rightarrow \mathrm{G}-\mathrm{C}$ or to $\mathrm{A}-\mathrm{T} \rightarrow \mathrm{T}-\mathrm{A}$ homologous transversion. A one-nucleotide gaps are formed opposite molecule of adenine $\mathrm{A}_{1}{ }^{*}, \mathrm{~A}_{3}{ }^{*}$ and $\mathrm{A}_{5}{ }^{*}$ is likely in the future they will be inserted correctly. Molecule of thymine can be inserted opposite $\mathrm{A}_{2}{ }^{*}$ and $\mathrm{A}_{4}{ }^{*}$, they may not result in mutations.

As we can see, from all possible rare tautomeric forms of adenine and thymine, only three, namely, $\mathrm{T}_{1}{ }^{*}, \mathrm{~T}_{4}{ }^{*}, \mathrm{~T}_{5}{ }^{*}$ and $\mathrm{A}_{1}{ }^{*}$, may cause untargeted base substitution mutations. Thus molecules of thymine $\mathrm{T}_{1} *$ and adenine $\mathrm{A}_{1} *$ in rare tautomeric form may result in transitions $\mathrm{A}-\mathrm{T} \rightarrow \mathrm{G}-\mathrm{C}$. Molecules of the thymine $\mathrm{T}_{1}{ }^{*}, \mathrm{~T}_{5} *$ and adenine $\mathrm{A}_{1} *$ in rare tautomeric forms can lead to homologous transversions $\mathrm{A}-\mathrm{T} \rightarrow \mathrm{T}-\mathrm{A}$, and molecules of the thymine $\mathrm{T}_{5} *$ and $\mathrm{T}_{4} *$ in rare tautomeric form may result in transversion $\mathrm{A}-\mathrm{T} \rightarrow \mathrm{C}-\mathrm{G}$. Thus, a rough estimate predicts that during the untargeted base substitution mutations formation which are formed during the formation of stable rare tautomeric forms of thymine and adenine, there is a $20 \%$ of transitions and $80 \%$ of transversions. As is known, untargeted mutagenesis is characterized by a high percentage of education transversions. ${ }^{34,36,66}$

\section{Discussion}

There is currently no complete understanding of the question of the nature and mechanisms of formation of untargeted bases substitution mutations. Mechanisms of various mutations are usually considered as part of the polymerase model of mutagenesis. I suggested, and developing alternative polymerase-tautomeric models of ultraviolet mutagenesis, bystander effects and genomic instability. In this paper, it is developed mechanisms of untargeted base substitutions mutations induced by molecules of thymine and adenine in rare tautomeric forms. Untargeted bases substitution mutations are substitution mutations that appear on the so-called not damaged DNA sites. Untargeted base substitution mutations can be caused, for example, irradiation with ultraviolet light of DNA molecules. As a result, as is known, cyclobutane pyrimidine dimers are formed. Ultraviolet radiation can lead to change in tautomeric states of DNA bases. Molecules of thymine and adenine can form five rare tautomeric forms. These rare tautomeric form will be stable if the corresponding nucleotides are part of cyclobutane dimers or are in a small neighborhood of them. If the tautomeric states in a pair of DNA bases are changed its tautomeric states change in both DNA bases. It changes in thymine, which is part of a cyclobutane dimer and adenine to which they are linked by hydrogen bonds.

Ii is considered a site of DNA, on which Cis-syn cyclobutane thymine dimers with bases in rare tautomeric forms appeared in both strands of DNA close to each other. Besides it is considered a site of DNA, on which in a small neighborhood of cyclobutane pyrimidine dimers with bases in the canonical tautomeric forms pairs base of adenine-thymine in rare tautomeric forms are formed. These sites are synthesized as a result of error-prone or SOS synthesis. Structural analysis indicates that canonical tautomeric forms of thymine cannot be incorporated opposite $\mathrm{A}_{1}{ }^{*}$. But canonical tautomeric forms of cytosine or adenine can be incorporated opposite $\mathrm{A}_{1}^{*}$. Rare $\mathrm{A}_{1}^{*}$ tautomer of adenine may result in a untargeted transition $\mathrm{A}-\mathrm{T} \rightarrow \mathrm{G}-\mathrm{C}$ or a untargeted homologous transversion $\mathrm{A}-\mathrm{T} \rightarrow \mathrm{T}-\mathrm{A}$. Molecule of thymine can be inserted opposite $\mathrm{A}_{2}$ *and $\mathrm{A}_{4}$ *; molecule of adenine can be inserted opposite $\mathrm{T}_{3}^{*}$; it is likely they will not result in mutations. The rare $\mathrm{A}_{3}{ }^{*}, \mathrm{~A}_{5}{ }^{*}$ and $\mathrm{T}_{2} *$ tautomers do not form hydrogen bonds with any canonical tautomers of DNA bases. So they cannot result in the base substitution mutations. Rare $\mathrm{T}_{1}$ * tautomer of thymine may result in $\mathrm{A}-\mathrm{T} \rightarrow \mathrm{G}$-Cuntargeted transition or $\mathrm{A}-\mathrm{T} \rightarrow \mathrm{T}$-Auntargeted homologous transversion. Molecules of the thymine in rare tautomeric form $\mathrm{T}_{4} *$ may result in transversion $\mathrm{A}-\mathrm{T} \rightarrow \mathrm{C}-\mathrm{G}$ only. Rare $\mathrm{T}_{5} *$ tautomer can result in transversion $\mathrm{A}-\mathrm{T} \rightarrow \mathrm{C}-\mathrm{G}$ or homologous transversions $\mathrm{A}-\mathrm{T} \rightarrow \mathrm{T}-\mathrm{A}$.

Thus, it is shown that the relationship between the type of primary DNA damage and the resulting kinds of mutations is not always simple. The same potential mutation can lead to transition or transversions. Which the mutation is formed depends on kind of rare tautomeric form of corresponding bases and a specialized DNA polymerase which is involved in DNA synthesis. The molecule of thymines $\mathrm{T}_{1}^{*}, \mathrm{~T}_{4}{ }^{*}, \mathrm{~T}_{5}$ * and of adenine $\mathrm{A}_{1}$ * located near the cyclobutane pyrimidine dimers may cause untargeted base substitution mutations. This conclusion is reached taking into account the fact that there is a control of the side groups of bases in the synthesis of DNA. ${ }^{154}$ If the mutagenic load is such that such control does not work, then it may appear Hoogsteen ${ }^{155,156}$ base pairs. Polymerase-tautomeric model predicts that under the formation of untargeted base substitution mutations $20 \%$ of transitions and $80 \%$ of transversions are formed. As is known, untargeted mutagenesis is characterized by a high percentage of education transversions.

The term untargeted mutations suggest that these mutations are formed on undamaged DNA sites. As it is have shown in this paper, this is not right. It should be assumed that untargeted mutations are a mutations appearing on DNA damages unable to stop the synthesis of DNA. This hypothesis was tested by biological methods only. Firmly established facts show that the so-called untargeted mutations appear on DNA sites, in which, using biological methods, no DNA damages was found. This does not mean that using other methods such as thermally stimulated luminescence, such DNA damages are not to be found. It is clear that in order to explain the nature of untargeted base substitutions mutations have not the slightest need to involve the ideas used now to explain bystander effects. They are easily and naturally explained by polymerase-tautomeric model.

Some substances, for example, xenobiotics, promote oxidative stress with the release of free radicals. ${ }^{157}$ Free radicals can change the tautomeric forms of DNA bases by exactly the same mechanism as ultraviolet irradiation of DNA. This can lead to targeted and untargeted mutagenesis, as well as to the instability of the genome. Therefore, the polymerase-tautomeric model is able to explain the mechanisms formation of targeted base substitution mutations, targeted insertions, targeted deletions, targeted complex insertion, targeted base substitution mutations and hot and cold spots of UV-induced mutagenesis. The polymerase-tautomeric model for bystander effects is able to explain the mechanisms formation for delayed targeted base substitution mutations and untargeted base substitution mutations.

\section{Acknowledgements}

None.

\section{Conflict of interest}

Author declares that there is no conflict of interest.

\section{References}

1. Bernstein C, Prasad AR, Nfonsam V, et al. DNA damage, DNA repair and cancer, new research directions in DNA repair. INTECH. 2013. p. 232.

Citation: Grebneva HA.A polymerase tautomeric model for radiation induced bystander effects: a model for untargeted base substitution mutagenesis during error prone and SOS replication of double stranded DNA containing thymine and adenine in rare tautomeric forms. Int J Mol Biol Open Access. 20I7;2(2):63-74. DOI: 10.15406/ijmboa.2017.02.00018 
2. Berger MF, Hodis E, Heffernan TP, et al. Melanoma genome sequencing reveals frequent PREX2 mutations. Nature. 2012;485(7399):502-506.

3. Karotki AV, Baverstock K. What mechanisms/processes underlie radiation-induced genomic instability? Cell Mol Life Sci. 2012;69(20):3351-3360

4. Little JB. Radiation carcinogenesis. Carcinogenesis. 2000;21(3):397-404.

5. Little JB. Genomic instability and bystander effects: a historical perspective. Oncogene. 2003;22(45):6978-6987.

6. Suzuki K, Ojima M, Kodama S, et al. Radiation-induced DNA damage and delayed induced genomic instability. Oncogene. 2003;22(45):6988-6993.

7. Niwa O. Radiation induced dynamic mutations and transgenerational effects. J Radiat Res. 2006;47(1):B25-B30.

8. Whiteside JR, Allinson SL, Trevor J, et al. Timeframes of UVA-induced bystander effects in human keratinocytes. Photochem Photobiol. 2011;87(2):435-440

9. Morgan WF, Sowa MB. Non-targeted effects induced by ionizing radiation: Mechanisms and potential impact on radiation induced health effects. Cancer Lett. 2015;356(1):17-21.

10. Kadhim M, Salomaa S, Wright E, et al. Non-targeted effects of ionising radiation-implications for low dose risk. Mutat Res. 2013;752(2):84-98.

11. Lyng FM, Semour CB, Mothersill C. Early events in the apoptotic cascade initiated in cells treated with medium from the progeny of irradiated cells. Radiat Prot Dosimetry. 2001;99(1-4):169-172.

12. Mothersill C, Morgan G, McNeill F, et al. A role for bioelectric effects in the induction of bystander signals by ionizing radiation? Dose-Response. 2007;5(3):214-229.

13. Campa A, Balduzzi M, Dini V, et al. The complex interactions between radiation induced non-targeted effects and cancer. Cancer Lett. 2015;356(1):126-136.

14. Averbeck D. Non-targeted effects as a paradigm breaking evidence. Mutat Res. 2010;687(1-2):7-12.

15. Watanabe M. The first target of radiation carcinogenesis is not DNA. Int Congress Series. 2015;42(13):2409-2413.

16. Wright EG. Manifestations and mechanisms of non-targeted effects of ionizing radiation. Mutat Res. 2010;687(1-2):28-33.

17. Morgan WF. Is there a common mechanism underlying genomic instability, bystander effects and other non targeted effects of exposure to ionizing radiation? Oncogene. 2003;22(45):7094-7099.

18. Tomasetti C, Vogelstein B. Variation in cancer risk among tissues can be explained by the number of stem cell divisions. Science. 2015;347(6217):78-81.

19. Maor-Shoshani A, Reuven NB, Tomer G, et al. Highly mutagenic replication by polymerase $\mathrm{V}(\mathrm{UmuC})$ provides a mechanism for SOS untargeted mutagenesis. Proc Natl Acad Sci USA. 2000;97(2):565-570.

20. Tang M, Pham P, Shen X, et al. Roles of Escherichia coli DNA polymerase IV and V in lesion-targeted and untargeted SOS mutagenesis. Nature. 2000;404(6781):1014-1018.

21. Pham P, Bertram JG, O'Donnell M, et al. A model for SOS-lesion-targeted mutations in Escherichia coli. Nature. 2001;408(6810):366-370.

22. Taylor J-S. New structural and mechanistic insight into the A-rule and the instructional and non-instructional behavior of DNA photoproducts and other lesions. Mutat Res. 2002;510(1-2):55-70

23. Tang M, Shen X, Frank EG, et al. UmuD' (2)C is an error-prone DNA polymerase Escherichia coli pol V. Proc Natl Acad Sci USA 1999;96(16):8919-8924.
24. Grebneva HA. A Polymerase-tautomeric model for targeted substitution mutations formation during error-prone and SOS replication of doublestranded DNA, containing cis-syn cyclobutane cytosine dimers. Int J Mol Biology: Open Access. 2016;1(1):1-16.

25. Strauss BS. The "A" rule revisited: polymerases as determinants of mutational specificity. DNA Repair. 2002;1(2):125-135.

26. Christensen JR, LeClerc JE, Tata PV, et al. UmuC function is not essential for the production of all targeted lacI mutations induced by ultraviolet light. J Mol Biol. 1988;203(3):635-641.

27. Lawrence CW, Gibbs PE, Borden A, et al. Mutagenesis induced by single UV photoproducts in E. Coli and yeast. Mutat Res. 1993;299(3-4):157-163.

28. Lawrence CW, Christensen RB. The mechanism of untargeted mutagenesis in UV-irradiated yeast. Mol Gen Genet. 1982;186(1):1-9.

29. Wood RD, Hutchinson F. Non-targeted mutagenesis induced by ultraviolet light in Escherichia coli. J Mol Biol. 1984;173:293-305.

30. Kunz BA, Glickman BW. The role of pyrimidine dimers as premutagenic lesions: a study of targeted vs. untargeted mutagenesis in the lacI gene of Escherichia coli. Genetics. 1984;106(3):347-364.

31. Brotcorne-Lannoye A, Maenhaut-Michel G. Role of RecA protein in untargeted UV mutagenesis of bacteriophage $\lambda$ : evidence for requirement for the dinB gene. Proc Natl Acad Sci USA. 1986;83(11):3904-3908.

32. Caillet-Fauquet P, Maenhaut-Michel G. Nature of the SOS mutator activity: genetic characterization of untargeted mutagenesis in Escherichia coli. Mole Gen Genet. 1988;213(2):491-498.

33. Kim SR, Matsui K, Yamada M, et al. Roles of chromosomal and episomal $\operatorname{din} B$ genes encoding DNA pol IV in targeted and untargeted mutagenesis in Escherichia coli. Mol Genet Genomics. 2001;266(2):207-215.

34. Fijalkowska IJ, Dunn RL, Schaaper RM. Genetic requirements and mutational specificity of the Escherichia coli SOS mutator activity. $J$ Bacteriol. 1997;179(23):7435-7445.

35. Nelson JR, Lawrence C, Hinkle DC. Thymine-thymine dimers bypass by yeast DNA polymerase $\zeta$. Science. 1996;272(5268):646-1649.

36. Watanabe-Akanuma M, Woodgate R, Ohta T. Enhanced generation of $\mathrm{A}: \mathrm{T} \rightarrow \mathrm{T}:$ A transitions in recA730lexA51(Def) mutant of Escherichia coli. Mutat Res. 1997;373(1):61-66.

37. Zhang Y, Yuan F, Wu X, et al. Response of human DNA polymeraset to DNA lesions. Nucleic Acids Research. 2001;29(4):928-935.

38. Livneh Z, Cohenfix O, Skaliter R, et al. Replication of damaged DNA and the molecular mechanism of ultraviolet light mutagenesis. Crit Rev Biochem Mol Biol. 1993;28(6):465-513.

39. Goodman MF. Coping with replication "train wrecks" in Escherichia coli using Pol V, Pol II and RecA proteins. Trends Biochem Sci. 2000;25(4):189-195.

40. Goodman MF. The discovery of error-prone DNA polymerase $\mathrm{V}$ and its unique regulation by RecA and ATP. $J$ Biol Chem. 2014;289(39):26772-26782.

41. Arana ME, Seki M, Wood RD, et al. Low-fidelity DNA synthesis by human DNA polymerase theta. Nucleic Acids Res. 2008;36(11):3847-3856.

42. Reuven NB, Arad G, Maor-Shoshani A, et al. The mutagenesis protein UmuC is a DNA polymerase activated by UmuD', RecA, and SSB and is specialized for translesion replication. J Biol Chem. 1999;274(45):31763-31766.

43. Kim S-R, Maenhaut-Michel G, Yamada M, et al. Multiple pathways for SOS-induced mutagenesis in Escherichia coli: an over expression of $\operatorname{din} B /$ dinP results in strongly enhancing mutagenesis in the absence of any exogenous treatment to damage DNA. Proc Natl Acad Sci USA. 1997;94(25):13792-13797.

Citation: Grebneva HA.A polymerase tautomeric model for radiation induced bystander effects: a model for untargeted base substitution mutagenesis during error prone and SOS replication of double stranded DNA containing thymine and adenine in rare tautomeric forms. Int J Mol Biol Open Access. 20I7;2(2):63-74. DOI: 10.15406/ijmboa.2017.02.00018 
44. Kunkel TA, Bebenek R. DNA replication fidelity. Annual Rev Biochem. 2000;69(1):497-529.

45. Kunkel TA, Erie DA. DNA mismatch repair. Annual Rev Biochem 2005;74:681-710.

46. Kool ET. Active site tightness and substrate fit in DNA replication. Annual Rev Biochem. 2002;71:191-219.

47. Radhakrishnan R, Arora K, Wang Y, et al. Regulation of DNA repair fidelity by molecular checkpoints: "gates" in DNA polymerase beta's substrate selection. Biochemistry. 2006;45(51):15142-15156.

48. Kirmizialtin S, Nguyen V, Johnson KA, et al. How conformational dynamics of DNA polymerase select correct substrates: experiments and simulations. Structure. 2012;20(4):618-627.

49. Hendel A, Ziv O, Gueranger Q, et al. Reduced efficiency and increased mutagenicity of translation DNA synthesis across a TT cyclobutane pyrimidine dimer, but not a TT 6-4 photoproduct, in human cells lacking DNA polymerase $\eta$. DNA Repair (Amst). 2008;7(10):1636-1646.

50. Vasquez-Del Carpio R, Silverstein TD, Lone S, et al. Role of human DNA polymerase $\kappa$ in extension opposite from a cis-syn thymine dimer. J Mol Biol. 2011;408(2):252-261.

51. Kasiviswanathan R, Gustafson MA, Copeland WC, et al. Human mitochondrial DNA polymerase $\gamma$ exhibits potential for bypass and mutagenesis at UV-induced cyclobutane thymine dimmers. J Biol Chem. 2012;287(12):9222-9229.

52. Ogino M, Okamura D, Yoshimura Y, et al. Nucleotide insertion opposite a cyclobutane pyrimidine dimer analogue caused from photoligation by a replicative DNA polymerase. Nucleic Acids Symp Ser (Oxf). 2006;50(1):125-126

53. Patel M, Jiang QF, Wood gate R, et al. A new model for SOS-induced mutagenesis: how RecA protein activates DNA polymerase V. Crit Rev Biochem Mol Biol. 2010;45(3):171-184.

54. Vaisman A, Takasawa K, Iwai S, et al. DNA polymerase t-dependent translesion replication of uracil containing cyclobutane pyrimidine dimers. DNA Repair. 2006;5(2):210-218.

55. Mc El hinny SAN, Stith CM, Burgers PMJ, et al. Inefficient proofreading and based error rates during inaccurate DNA synthesis by a mutant derivative of Saccharomyces cerevisiae DNA polymerase $\delta$. J Biol Chem. 2017;282(32):2324-2332.

56. LiY, Dutta S, Doublie S, et al. Nucleotide insertion opposite a cis-syn thymine dimer by a replicative DNA polymerase from bacteriophage T7. Nat Struct Mol Biol. 2004;11(8):784-790.

57. Biertümpfel C, Zhao Y, Kondo Y, et al. Structure and mechanism of human DNA polymerase $\eta$. Nature. 2010;465(7360):1044-1048.

58. Silverstein TD, Johnson RE, Jain R, Prakash L, et al. Structural basis for the suppression of skin cancers by DNA polymerase $\eta$. Nature. 2010;465(7301):1039-1043.

59. Lange SS, Takata K, Wood RD. DNA polymerases and cancer. Nat Rev Cancer. 2011;11:96-110.

60. Parris CN, Levy DD, Jessee J, et al. Proximal and distal effects of sequence context on ultraviolet mutational hotspots in a shuttle vector replicated in xeroderma cells. J Mol Biol. 1994;236(2):491-502.

61. Canella KA, Seidman MM. Mutation spectra in supF: approaches to elucidating sequence context effects. Mutat Res. 2000;450(1-2):61-73.

62. Little JB, Gorgojo L, Vetrovs H. Delayed appearance of lethal and specific gene mutations in irradiated mammalian cells. Int J Radiat Oncol Biol Phys. 1990;19(6):1425-1429.

63. Boesen JJ, Stuivenberg S, Thyssens $\mathrm{CH}$, et al. Stress response induced by DNA damage leads to specific, delayed and untargeted mutations. Molecular and General Genetics. 1992;234(2):217-227.
64. Harper K, Lorimore SA, Wright EG. Delayed appearance of radiation induced mutations at the Hprt locus in murine hemopoietic cells. Exp Hematol. 1997;25(3):263-269.

65. Miller JH, Low KB. Specificity of mutagenesis resulting from the induction of the SOS system in the absence of mutagenic treatment. Cell. 1984;37(2):675-682.

66. Levine JG, Schaaper RM, DeMarini DM. Complex frame shift mutations mediated by plasmid pKM101: mutational mechanisms deduced from 4-aminobiphenyl-induced mutation spectra in Salmonella. Genetics. 1994;136(3):731-746

67. DeMarini DM. Influence of DNA repair on mutation spectra in Salmonella. Mutat Res. 2000;450(1-2):5-17.

68. Wang CI, Taylor JS. In vitro evidence that UV-induced frame shift and substitution mutations at $\mathrm{T}$ tracts are the result of misalignmentmediated replication past a specific thymine dimer. Biochemistry. 1992;31(14):3671-3681

69. Seki M, Akiyama M, Sugaya Y, et al. Strand asymmetry of +1 frame shift mutagenesis at a homopolymeric run by DNA polymerase III holoenzyme of Escherichia coli. J Biol Chem. 1999;274(47):33313-33319.

70. Bzymek M, Lovett ST. Instability of repetitive DNA sequences: The role of replication in multiple mechanisms. Proc Natl Acad Sci USA. 2001;98(15):8319-8325.

71. Strand M, Prolla TA, Liskay RM, et al. Destabilization of tracts of simple repetitive DNA in yeast by mutations affecting DNA mismatch repair. Nature. 1993;365(6443):274-276.

72. Baase WA, Jose D, Ponedel BC, et al. DNA models of tri nucleotide frame shift deletions: the formation of loops and bulges at the primertemplate 7junction. Nucleic Acids Res. 2009;37(5):1682-1689.

73. Friedberg EC, Walker GC, Siede W, et al. DNA repair and mutagenesis part 3. USA; ASM Press: 2006.

74. Friedberg EC, Walker GC, Siede W. DNA repair and mutagenesis. USA, ASM Press: 1995. p. 22.

75. Kordyum VA. Problem of tumor origin as it is from the molecular genetics point of view. Biopolymers Cell (Ukr). 2001;17(2):109-139.

76. Watson JD, Crick FHC. The structure of DNA. Cold Spring Harbor Symp Quant Biol. 1953;18:123-131.

77. Grebneva HA. The heat deexitation as mechanism of double proton transitions in DNA. Dopovidi NAN Ukraine. 1994;2:73-75.

78. Grebneva HA. The irradiation of DNA by ultraviolet light: potential alterations and mutations. Mol Biol (Mosk). 1994;28(4):527-532.

79. Grebneva HA. Mechanisms of formation of potential mutations under cytosine dimers formation in result irradiation double-stranded DNA by ultraviolet light. Dopovidi NAN Ukraine. 2001;7:165-169.

80. Grebneva HA. The nature and possible mechanisms of potential mutations formation due to the appearance of thymine dimers after irradiating double-stranded DNA by ultra-violet light. Biopolymers and Cell (Ukraine). 2002;18(1):205-218.

81. Grebneva HA. Nature and possible mechanisms formation of potentia mutations arising at emerging of thymine dimers after irradiation of double-stranded DNA by ultraviolet light. $J$ of Mol Struct. 2003;645(2-3):133-143

82. Grebneva HA. A polymerase-tautomeric model of UV mutagenesis: Formation of rare tautomeric forms of cytosine and guanine in doublestranded DNA. Vestn Donets Nat Univ (Ukr). 2008;2:306-313.

83. Grebneva HA. A model for targeted substitution mutagenesis during SOS replication of double-stranded DNA containing cis-syn cyclobutane thymine dimers. Environ Mol Mutagen. 2006;47(9):733-745. 
84. Grebneva HA. Targeted mutagenesis caused by cytosine dimers and mechanism substitution mutation formation under SOS-replication after irradiation double-stranded DNA by ultraviolet light. Dopovidi NAN Ukraine 2001;8:183-189.

85. Grebneva HA. The molecular mechanisms derivation of mutation bases alteration after a post replication SOS-repair a DNA containing thymine dimers. Biopolymers Cell (Ukr). 2001;17(6):487-500

86. Grebneva HA. Targeted base-substitution mutations during the synthesis of double-stranded DNA containing cis-syn cyclobutane pyrimidine dimers. Vestn Donets Nat Univ (Ukr). 2009;1:323-330.

87. Grebneva HA. Mechanisms targeted insertions formation under synthesis of DNA molecule containing cis-syn cyclobutane cytosine dimers. Dopovidi NAN Ukraine. 2014;1(11):156-164

88. Grebneva HA. Mechanisms of targeted frameshift mutations - insertion formation under error-prone or SOS synthesis of DNA containing cissyn cyclobutane thymine dimers. Mol Biol (Mosk). 2014;48(4):457-467.

89. Grebneva HA. Mechanisms targeted deletions formation under synthesis of DNA molecule containing cis-syn cyclobutane thymine dimers Dopovidi NAN Ukraine. 2015;1(4):124-132.

90. Grebneva HA. A polymerase - tautomeric model for targeted frame shift mutations: deletions formation during error-prone or SOS replication of double-stranded DNA containing cis-syn cyclobutane thymine dimers. $J$ Phot Mat Technology. 2015;1(2):19-26.

91. Grebneva HA. Mechanisms of targeted complex insertions formation under synthesis of DNA molecule containing cis-syn cyclobutane thymine dimers. Dopovidi NAN Ukraine. 2015;1(5):145-154.

92. Grebneva HA. Nature and mechanisms of hot and cold spots of ultraviolet mutagenesis formation. Dopovidi NAN Ukraine. 2012;10:181-187.

93. Grebneva HA, Ivanov MO. The possible molecular mechanisms of untargeted type mutation under SOS replication of double-stranded DNA. Biopolymers Cell (Ukr). 2001;17(5):388-395.

94. Grebneva HA. Possible molecular mechanisms of untargeted mutagenesis upon a post-replication SOS repair after irradiating double-stranded DNA by ultraviolet light. Biopolymers Cell (Ukr). 2002;18(5):394-400.

95. Grebneva HA. Three sources of untargeted substitution mutations arising under irradiation DNA molecule by ultraviolet light. Dopovidi NAN Ukraine. 2013;1(1):143-150.

96. Grebneva HA. Polymerase-tautomeric model for mechanism of targeted delayed substitution mutations formation under synthesis of DNA containing cis-syn cyclobutane thymine dimers. Dopovidi NAN Ukraine. 2016;1(5):101-110.

97. Grebneva HA. Polymerase-tautomeric model for ultraviolet mutagenesis: targeted base substitution and frame shift mutations caused by cis-syn cyclobutane thymine dimers. USA; Lap Lambert Academic Press: 2017. p. 132.

98. Grebneva HA. Possible mechanism of formation of rare tautomeric forms of nucleotide bases on the example of UV-irradiation of DNA. Ukraine Physical Journal. 1992;37(11):1636-1642.

99. Mosse IB. Radio genetics effects in eukaryotic cells. In: Radiation mutagenesis and its role in evolution and selection. Moskow; Nauka: 1987. p. $73-83$.

100. Barltrop JA, Coyle JD. Excited states in organic chemistry. USA; Wiley: 1978. p. 446.

101. Vekshin NL. Photonic of biological structure. Russia; Puschino: 1988. p. 51 .

102. Vekshin NL. Transference of excitation in macromolecules. Result of Science and Technology. Radiation Chemistry Photochemistry, VINITI, Moskow; 1989; 7:1-164.
103. Grebneva HA, Tolpygo KB. Electrostatic interaction, protonic potential and properties of hydrogen bonds in the system of guanine - cytosine Ukraine Physical Journal. 1988;33(10):1456-1462.

104. Grebneva HA, Tolpygo KB. Influence of the hydrogen bonds between paired bases of DNA on fluctuations of the side groups. Ukraine Physical Journal. 1989;34(12):1791-1796.

105. Tolpygo KB, Grebneva HA. Effect of the state of h-b-1 hydrogen bond of the character of some atom vibrations in guanine-cytosine pair of the DNA molecule. Int J Quant Chem. 1996;57(2):219-227.

106. Grebneva HA, Tolpygo KB. Crystalline and local vibrations of paired bases in poly $(\mathrm{dG})$-poly $(\mathrm{dC})$ interacting with the h-b-1 hydrogen bond. Int J Quant Chem. 1997;62(1):115-124.

107. Grebneva HA, Tolpygo KB. Crystalline and local vibrations of the atom of base pair in poly (dG)-poly $(\mathrm{dC})$ which interact with the h-b-1 hydrogen bond. Zhurnal Fiz Khimii. 1997;71(5):920-925.

108. Grebneva HA. A new semi empirical potential function for hydrogen bonds and its possible use in studying the DNA molecule. J Mol Struct. 1993;296(1):127-132.

109. Grebneva HA. Proton potential for broad spectrum of hydrogen bond length in water dimer. Zhurnal Strukturnoy Khimii. 1997;38(2):422-430.

110. Sokolov ND, Chulanovsky BM. Hydrogen Bond. Nauka, Moskow; 1964 p. 340.

111. Grebneva HA, Tolpygo KB. The heat deexcitation of hydrogen bond protons in paired bases of DNA molecules. Studia Biophysica. 1990;135(1):115-125.

112. Grebneva HA, Tolpygo KB. Heat transitions in DNA molecule. The lifetime of excited h-b-1 hydrogen bond in paired bases guaninecytosine. Biofizika. 1990;35(3):395-398.

113. Tishchenko OV, Kryachko ES, Staninets VI. Quantum-chemical study of hydrogen atom transfers in phenol $\left(\mathrm{NH}_{2}\right)$ complex. Theoretical Experimental Chimie. 1999;35(1):331-337.

114. Leonenko ZV, Grizan NP. Quantum-chemical investigations of intramolecular transfer of hydrogen atom in o-methylated phenone and 1-alkilantrachenones. Zhurnal Strukturnoy Khimii. 1997;38(2):645-654.

115. Minaev BF, Minaeva VA, Lyzhenkova II, et al. Quantum-chemical approach to the biochemical mechanism of nicotineamid action. Theoretical Experimental Chimiya. 1999;35(1):277-283.

116. Zundel G. Hydrogen bonds with large proton polarizability and proton transfer processes in electrochemistry and biology. In: Prigogine I, Struart A, et al. editors. Advances in Chemical Physics. John Wiley \& Sons, USA; 2000. p. 217.

117. Volkov SN. Semi-open state of double-stranded spiral of DNA. Molecular Biology (Mosk). 1995;29(3):1086-1094.

118. Hovorun DM. A structural-dynamic model on spontaneous semi open states in DNA. Biopolymers and Cell. 1997;13(1):39-45.

119. Clementi E, Corongiu G, Detrich J, et al. Parallelism in study in DNA pairs as an example. International Journal of Ouantum Chemistry. 1984;18(18):601-618.

120. Gorb L, Podolyan Y, Dziekonski P, et al. Double-proton transfer in adenine-thymine and guanine-cytosine base pairs. A post-Hartree-Fock ab initio study. J Am Chem Soc. 2004;126(32):10119-21019.

121. Brovarets OO, Hovorun DM. Can tautomerization of the A-T WatsonCrick base pair via double proton transfer provoke point mutations during DNA replication? A comprehensive QM and QTAIM analysis. $J$ Biomol Struct Dyn. 2014;32(1):127-154.

122. Raghunathan G, Kieber-Emmons T, Rein R, et al. Conformation features of DNA containing a cis-syn photodimer. J Biopol Struct Dyn. 1990;7(4):899-913.

Citation: Grebneva HA.A polymerase tautomeric model for radiation induced bystander effects: a model for untargeted base substitution mutagenesis during error prone and SOS replication of double stranded DNA containing thymine and adenine in rare tautomeric forms. Int J Mol Biol Open Access. 20I7;2(2):63-74. DOI: 10.15406/ijmboa.2017.02.00018 
123. Cooney MG, Miller JH. Calculated distortions of duplex DNA by a cis, syn cyclobutane thymine dimer are unaffected by a 3' TpA step. Nucleic Acids Res. 1997;25(7):1432-1436.

124. McAteer K, Jing Y, Kao J, et al. Solution-state structure of a DNA dodecamer duplex containing a cis-syn thymine cyclobutane dimer, the major UV photoproduct of DNA. J Mole Biol. 1998;282(5):1013-1032.

125. Yamaguchi H, van Aalten DM, Pinak M, et al. Essential dynamics of DNA containing a cis.syn cyclobutane thymine dimer lesion. Nucleic Acids Res. 1998;26(8):1939-1946.

126. Seeman NC, Rosenberg JM, Rich A. Sequence-specific recognition of double helical nucleic acids by proteins. Proc Natl Acad Sci USA 1976;73(3):804-808

127. Petruska J, Goodman MF, Boosalis MS, et al. Comparison between DNA melting thermodynamics and DNA polymerase fidelity. Proc Natl Acad Sci USA. 1988;85(17):6252-6256.

128. Gorb L, Podolyan Y, Leszczynski J, et al. A quantum-dynamics study of the prototropic tautomerism of guanine and its contribution to spontaneous point mutations in Escherichia coli. Biopolymers. 2002;61(1):77-83.

129. Bebenek K, Pedersen LC, Kunkel T. Replication infidelity via a mismatch with Watson-Crick geometry. Proc Natl Acad Sci USA. 2011;108(5):1862-1867.

130. Wang W, Hellinga HW, Beese LS. Structural evidence for the rare tautomer hypothesis of spontaneous mutagenesis. Proc Natl Acad Sci USA. 2011;108(43):17644-17648.

131. Xia S, Konigsberg WH. Mispairs with Watson-Crick base-pair geometry observed in ternary complexes of an RB69 DNA polymerase variant. Protein Sci. 2014;23(4):508-513.

132. Singh V, Fedeles BI, Essigmann JM. Role of tautomerism in RNA biochemistry. RNA. 2015;21(1):1-13.

133. Li D, Fedeles BI, Singh V, et al. Tautomerism provides a molecular explanation for the mutagenic properties of the anti-HIV nucleoside 5-aza-5,6-dihydro-2'-deoxycytidine. Proc Natl Acad Sci USA 2014;111(32):E3252-E3259.

134. Peng CS, Baiz CR, Tokmakoff A. Direct observation of ground-state lactam-lactim tautomerization using temperature-jump transient 2D IR spectroscopy. Proc Natl Acad Sci USA. 2013;110(23):9243-9248.

135. Nowak MJ, Lapinski L, Kwiatkowski JS, et al. Molecular structure and infrared spectra of the DNA bases and their derivatives: theory and experiment. In: Leszczynski J, editor. Computational Chemistry. Reviews of Current Trends. World Scientific Publishing, Singapore; 1997;2(1):140-216.

136. Fielden EM, Neill PO. The early effects of radiation on DNA. Springer Berlin; 1991. p. 230.

137. Halliwell B, Aruoma OI. DNA and free radicals. UK; Horwood: 1993. p. 284.

138. Furukohri A, Goodman MF, Maki H. Dynamic polymerase exchanges with Escherichia coli DNA polymerase IV replacing DNA polymerase III on the sliding clamp. J Biol Chem. 2008;283(17):11260-11269.

139. Washington MT, Johnson RE, Prakash S, et al. Accuracy of thyminethymine dimer bypass by Saccharomyces cerevisiae DNA polymerase $\eta$ Proc Natl Acad Sci USA. 2000;97(7):3094-3099.
140. Johnson RE, Haracska L, Prakash S, et al. Role of DNA polymerase $\eta$ in the bypass of a (6-4) TT photoproduct. Mol Cell Biol. 2001;21(10):3558-3563.

141. Lawrence CW. Cellular roles DNA polymerase Cand Rev1 protein. DNA repair. 2002;1(6):425-435.

142. Washington MT, Prakash L, Prakash S. Mechanism of nucleotide incorporation opposite a thymine-thymine dimer by yeast DNA polymerase ๆ. Proc Natl Acad Sci USA. 2003;100(21):12093-12098.

143. Kozmin SG, Pavlov YI, Kunkel TA, et al. Roles of Saccharomyces cerevisiae DNA polymerases Pol $\eta$ and Pol $\zeta$ in response to irradiation by simulated sunlight. Nucleic Acids Research. 2003;31(15):4541-4552.

144. Gibbs PE, McDonald J, Woodgate R, et al. The relative roles in vivo of Saccharomyces cerevisiae Pol $\eta$, Pol $\zeta$, Rev1 protein and Pol32 in the bypass and mutation induction of an a basic site, T-T (6-4) photo adduct and T-T cis-syn cyclobutane dimer. Genetics. 2005;169(2):575-582.

145. Wang Y, Woodgate R, McManus TP, et al. Evidence that in xeroderma pigmentosum variant cells, which lack DNA polymerase $\eta$, DNA polymerase icauses the very high frequency and unique spectrum of UVinduced mutations. Cancer Res. 2007;67(7):3018-3026

146. Shachar S, Ziv O, Avkin S, et al. Two-polymerase mechanisms dictate error-free and error-prone translesion DNA synthesis in mammals. EMBO J. 2009;28(4):383-393.

147. Mikhailov VS. Eukaryotic DNA polymerases. Mol Biol (Mosk). 1999;33(4):498-511.

148. Chen X, Zuo S, Kelman Z, et al. Fidelity of eukaryotic DNA polymerase delta holoenzyme from Schizosaccharomyces pombe. J Biol Chem. 2000;275(23):17677-17682.

149. Shimizu K, Hashimoto K, Kirchner JM, et al. Fidelity of DNA polymerase choloenzyme from budding yeast Saccharomyces cerevisiae. J Biol Chem. 2002;277(40):37422-37429.

150. Krutyakov VM. Rational regulation of DNA polymerase-mediated mutagenesis and autonomous $3^{\prime} \rightarrow 5^{\prime}$-exonucleases. Molecular Biology (Mosk). 1998;38(5):696-705.

151. Krutyakov VM. Antimutagenic role of autonomous 3' $\rightarrow$ 5'-exonucleases Mol Biol (Mosk). 2004;38:696-705.

152. Gibbs PEM, McGregor WG, Maher VM, et al. A human homolog of the Saccharomyces cerevisiae REV3 gene, which encodes the catalytic subunit if DNA polymerase $\zeta$. Proc Natl Acad Sci USA. 1998;95(12):6876-6880.

153. Poltev VI, Shulyupina NV, Bruskov VI. Molecular mechanisms of right biosynthesis of nucleic asides. Comparison of computer modeling results with experimental data. Mol Biol (Mosk). 1998;32(2):268-276.

154. Hoogsteen K. The crystal and molecular structure of a hydrogenbonded complex between 1-methylthymine and 9-methyladenine. Acta Crystallographica. 1963;16:907-916.

155. Nikolova EV, Kim E, Wise AA, et al. Transient Hoogsteen base pairs in canonical duplex DNA. Nature. 2011;470(7335):498-502.

156. Martins IJ. Increased risk for obesity and diabetes with neurodegeneration in developing countries. J Molecular Genetic Medicine. 2013;S1:001.

Citation: Grebneva HA.A polymerase tautomeric model for radiation induced bystander effects: a model for untargeted base substitution mutagenesis during error prone and SOS replication of double stranded DNA containing thymine and adenine in rare tautomeric forms. Int J Mol Biol Open Access. 20 I7;2(2):63-74. DOI: 10.15406/ijmboa.2017.02.00018 